\title{
INVENTÁRIO DE BENS CULTURAIS: CONHECER E COMPREENDER.
}

MARLY RODRIGUES, MEMÓRIAS ASSESSORIA E PROJETOS, SÃO PAULO, SÃO PAULO, BRASIL. Doutora em História. Diretora de Memórias Assessoria e Projetos. E-mail: marly@mem.com.br

DOI

http://dx.doi.org/10.11606/issn.1980-4466.v0iesp21p31-48 


\section{INVENTÁRIO DE BENS CULTURAIS: CONHECER E}

COMPREENDER.

MARLY RODRIGUES

\section{RESUMO}

A partir de inventários realizados na década de 1970 pelo Conselho de Defesa do Patrimônio Histórico, Arqueológico, Artístico e Turístico (Condephaat) busca-se identificar algumas razões e a dinâmica que vêm impedindo a adoção de práticas sistemáticas de identificação de bens culturais e os efeitos disso na sociedade.

\section{PALAVRAS-CHAVE}

Patrimônio cultural. Bens culturais. Políticas públicas. 


\section{KNOWING AND UNDERSTANDING THE INVENTORY OF CULTURAL ASSETS. \\ MARLY RODRIGUES}

\section{ABSTRACT}

Based on inventory listings conducted in the 1970s by the Conselho de Defesa do Patrimônio Histórico, Arqueológico, Artístico e Turístico (Condephaat), the article aims to identify some of the reasons and dynamics which have created obstacles for using systematic practices to identify cultural assets, as well as the consequences of those obstacles for society.

\section{KEYWORDS}

Cultural heritage. Cultural assets. Public policy. 
A concepção de patrimônio, expressa na Constituição de 1988, reafirmou-o como representação da cultura e suporte de memórias da sociedade. Tal definição acentuou a responsabilidade de o estado preservá-lo como vetor relacionado à constante recriação simbólica da vida, pessoal e social, à compreensão da dinâmica histórica do presente e à manutenção da boa qualidade do meio ambiente. Esse último aspecto abriria aos cidadãos a possibilidade de defesa do direito à memória, garantia que viria a se firmar como parte do direito à sadia qualidade de vida. ${ }^{1}$

Embora estes tenham sido importantes avanços no sentido de aproximar sociedade e órgãos de preservação do patrimônio, sua atuação no estado de São Paulo ainda é, em grande parte e por razões diversas, vista como insatisfatória. Se em um extremo há os que consideram que a preservação constitui impedimento à livre iniciativa, em outro, parte considerável da população não se sente representada no conjunto de bens tombados, uma

\footnotetext{
1. Esta possibilidade funda-se em vários estudos jurídicos, entre os quais os de José Afonso da Silva. O autor defende o conceito de meio ambiente globalizante, isto é, composto por três vertentes: natural, artificial e cultural. $\mathrm{Na}$ artificial, se inclui o espaço urbano construído. Na cultural, o patrimônio material e intangível. Correia (2001, p. 41) refere-se ao ambiente cultural como "um dos eixos em torno dos quais gravita e se desenvolve a vida humana, condicionando-lhe também a existência"; ele "agrega valores fundamentais da comunidade, retratando a sua memória, a sua identidade e a sua história, afigurando-se incontestável, pois, a sua decisiva contribuição para uma sadia qualidade de vida" (MARINO, 2015).
} 
vez que o reconhecimento do valor cultural por meio do tombamento resulta de valores externos à sua experiência individual e coletiva. A distância entre as ações e os efeitos sociais da proteção era um tema antes bastante discutido entre os preservacionistas, mas parece ter perdido a atualidade, embora seus efeitos ainda sejam perceptíveis.

A dinâmica dos órgãos de preservação vem resistindo à inclusão em sua rotina de formas democráticas de participação da sociedade, como as audiências públicas, adotadas em vários setores do governo após a democratização do país. O canal desde sempre acessível a todos, indistintamente, é o da solicitação de abertura de estudo de tombamento, uma vez que os conselhos aos quais cabe decidir a respeito são compostos por representantes de instituições, como universidades, e de setores da administração pública. Canal legítimo e positivo, as solicitações de balcão acabam por orientar uma parte essencial das ações dos órgãos, a proteção, cujo instrumento jurídico se restringe ainda ao tombamento. As demais ações, preservação e valorização de bens, decorrem da proteção.

O predomínio da prática de abertura de estudos de tombamento caso a caso, a partir de pedidos da sociedade, estabelece uma quase total exclusividade que sustenta exclusões, uma vez que os pedidos são muitas vezes motivados por interesses particulares, tais como os de partilha de heranças, ou casuísticos, por exemplo, quando há ameaças de destruição, e, mais raramente, expressam preocupações com a preservação da memória.

Nos órgãos de preservação que atuam em São Paulo, os casos de abertura de estudos de tombamento a partir de trabalhos sistemáticos de identificação ainda não se constituíram em prática cotidiana, o que remete à possibilidade de ser este um fator da distância entre eles e a sociedade. Limitar a rotina às solicitações externas é reduzir a obrigação constitucional de o estado preservar a cultura, subordinando-a à imprevisibilidade dos pedidos e, em consequência, da atuação dos órgãos de preservação sem que estes possam se adiantar às iniciativas "destruidoras" públicas ou privadas. Tal limite tende também a empobrecer a representatividade social do conjunto de bens tombados, uma vez que exclui avaliações comparativas eficazes somente a partir da análise de um universo de bens semelhantes ao qual se aplicam critérios referenciados em conceitos e procedimentos consagrados 
em âmbito nacional e internacional no campo da proteção a bens culturais e de disciplinas de conhecimento que possibilitem o entendimento amplo sobre a dinâmica da sociedade contemporânea, à qual cabe o usufruto dos bens que representam seus valores culturais.

O atual quadro da preservação em São Paulo espelha procedimentos atávicos, e parece desconhecer que a dinâmica da preservação alinha-se à da sociedade e exige constantes adequações conceituais e de procedimentos, de modo a atender a diversidade de suas finalidades. $O$ desafio que se coloca é a compreensão das razões que levaram a esta situação. Muitas se prendem ao campo político, entendido na amplitude do termo; outras são escolhas metodológicas. Ambas aparecem no caso do Conselho de Defesa do Patrimônio Histórico, Arqueológico, Artístico e Turístico (Condephaat), cujas tentativas de renovar procedimentos técnicos serão aqui observadas a partir de ações de inventário realizadas na década de 1970, quando se processavam grandes transformações no país e no conceito e alcance social do patrimônio.

\section{HISTORICIZANDO}

Em 1837, a França tornou-se pioneira na formalização da prática de inventário. Entre 1917 e 1935, as primeiras propostas de proteção ao patrimônio brasileiro já incluíam o inventário como forma de reconhecer e selecionar os monumentos mais significativos a serem preservados. Desde a criação do Instituto do Patrimônio Histórico e Artístico Nacional (Iphan), em 1937, foram também incontáveis as referências à importância do inventário como procedimento metódico. ${ }^{2}$ De há muito, portanto, o "conhecer" é apontado como condição do "proteger"; a necessidade de realização de inventários seria internacionalmente reforçada na década de $1970 .{ }^{3}$ No Brasil, ela já o fora no relatório da missão da Unesco que, em 1966-1967, visitou o país, chefiada por Michel Parent. O especialista recomendou a inserção do patrimônio brasileiro

\footnotetext{
2. Entre os projetos apresentados à Câmara, destaco o de Augusto Lima, em 1924. Sobre as práticas mais recentes de inventário no Iphan, ver Motta et al. (1998).

3. Recomendação relativa à salvaguarda dos conjuntos históricos e sua função na vida contemporânea. 19a Conferência Geral da Unesco, Nairobi, 26.11.1976 (CURY, 2009).
} 
no circuito turístico internacional, para o que seria necessário desenvolver ações de apoio, entre as quais um inventário dos bens artísticos e naturais (LEAL, 2008). ${ }^{4}$

Essa recomendação deu um sentido pragmático à realização de inventários, o que correspondia ao espírito então reinante no país; era preciso conhecer o acervo para oferecer mercadorias de consumo cultural que promovessem o aproveitamento econômico do patrimônio. Era de esperar que, a partir do Instituto do Patrimônio Histórico e Artístico Nacional (Iphan), o inventário passasse a ser uma ação prioritária e anterior à proteção de bem culturais; mas isso não ocorreu, embora o turismo passasse a integrar os horizontes da preservação, como expressa a denominação do órgão estadual criado em São Paulo no ano de 1968, o Conselho de Defesa do Patrimônio Histórico, Arqueológico, Artístico e Turístico (Condephaat). ${ }^{5}$

A vinda das missões da Unesco ao Brasil coincide com um período de extensa e profunda transformação nas formas de vida e nos espaços urbanos, o que concorreu para a crescente pressão da sociedade no sentido da preservação de bens culturais e ambientais, uma vez que as condições econômicas, especialmente entre 1968-1972, propiciaram a acelerada expansão de obras públicas de porte e, também, de investimentos particulares no setor imobiliário, ambos resultando na mudança de espaços, especialmente nos bairros tradicionais e áreas ao redor das cidades de grande e médio portes. $O$ inventário, então na pauta das discussões internacionais sobre patrimônio, tornou-se um tema constante também no país. A Declaração de Amsterdã, de 1975, o classificou como instrumento básico para o planejamento urbano e físico territorial, cujas informações deveriam ser amplamente difundidas, pois forneceriam dados essenciais para a conservação. No ano seguinte, o documento da $19^{\text {a }}$ Conferência Geral da Unesco, em Nairobi, abordou o inventário em relação à gestão do patrimônio. ${ }^{6}$

\footnotetext{
4. Leal, 2008. O Compromisso de Salvador, 1971, incluiu entre suas recomendações que o Iphan realizasse convênios com universidades para a realização de inventários sistemáticos.

5. O art. 128, da Constituição de 1967 do Estado de São Paulo, criou o Condephaat; a Lei n. 10.247, de 1968 dispôs sobre sua competência, organização e funcionamento; em 1969, o Decreto n. 149 dispõe sobre o tombamento de bens de valor histórico e artístico.

6. Ver Cury (2009), respectivamente p. 199 e 217.
} 
No país inaugurou-se, então, uma curta temporada de realização de inventários sistemáticos. Curiosamente, eles não foram promovidos por órgãos de preservação, e entre suas motivações se incluía o aproveitamento econômico dos bens tombados com finalidades turísticas. Em 1973, na Bahia, a Secretaria da Indústria, Comércio e Turismo, iniciou o pioneiro Inventário de Proteção do Acervo Cultural da Bahia (Ipac-BA), cuja metodologia, segundo um de seus idealizadores, o arquiteto Paulo Ormindo de Azevedo, foi inspirada no modelo europeu. O mesmo ocorreria em Minas Gerais, através do Centro de Desenvolvimento Urbano da Fundação João Pinheiro, e, na década seguinte, em Pernambuco e na cidade de São Paulo (AZEVEDO, 1987, p. 84).

\section{NA METRÓPOLE PAULISTANA}

$\mathrm{Na}$ década de 1970, a cidade de São Paulo passou por grandes mudanças espaciais, entre elas as decorrentes da implantação do metrô (19681974), e, também, administrativas, estas representadas pela criação da Região Metropolitana (1973), e por novas regras de zoneamento (Lei $\mathrm{n}^{\circ} 7.805$, de 1.11.1972) que incluíram a criação de áreas sujeitas a medidas específicas, entre as quais a Z8-200, referente a áreas históricas ou de valor cultural ou paisagístico cuja efetivação se deu apenas em 1975, pela Lei no 8.328 , de 2 de dezembro.

A definição das áreas a serem classificadas em razão da incidência de bens culturais exigiu a realização de inventários, entre eles o da área central da cidade, que se tornaria paradigmático. Promovido pela Coordenação Geral do Planejamento (Cogep), criada em 1972 e, posteriormente, transformada em Secretaria Municipal de Planejamento, esse inventário foi coordenado pelos arquitetos Carlos Lemos e Benedito Lima de Toledo, ambos profissionais com atuação na área de preservação de bens culturais. Inspirados na experiência francesa de inventários, realizada na década de 1960, escolheram organizá-lo a partir de "manchas", isto é, de áreas de concentração de edifícios representativos do processo de urbanização. Outro inventário, realizado em 1975 pela Cogep em colaboração com a recém-instalada Divisão de Preservação do Departamento do Patrimônio Histórico (DPH), da 
Secretaria Municipal de Cultura, abrangeu uma área de impacto do metrô na Zona Leste e, também, se tornaria uma referência. ${ }^{7}$

Em ambos os casos, o conceito explicitado como referência para a elaboração do inventário foi o de "patrimônio ambiental urbano", cujo desenvolvido se deu no âmbito da Empresa Metropolitana da Grande São Paulo S. A. (Emplasa), cuja criação foi formalizada em 1975, com a instalação da Secretaria de Estado dos Negócios Metropolitanos (SNM). Cabiam a Emplasa ações relativas à Área Metropolitana de São Paulo. A configuração de patrimônio ambiental urbano se deu com a participação de profissionais atuantes na área de preservação. $O$ conceito fundou-se na percepção da cidade como um artefato cultural em constante transformação, no qual as ações de preservação deveriam se orientar pela configuração presente do território (MENESES, 1978). Pretendia-se inverter a direção das ações preservacionistas; tratava-se de preservar o presente e o passado nele integrados, mantendo-se a paisagem urbana como um fator de manutenção de referências espaciais e afetivas e de criação de sentidos para os espaços urbanos, fator essencial para a alimentação das imagens mentais sobre a cidade (MENESES, 1978).

Contemporâneo à ampliação da ideia de patrimônio histórico-arquitetônico para a de patrimônio cultural, o patrimônio ambiental urbano envolvia enorme complexidade conceitual e sua aplicação dependia da concorrência de profissionais de diferentes especialidades, o que, em parte, explica as diversas interpretações que recebeu e o fato de ele não ter sido traduzido operacionalmente. Diversamente do ocorrido na Bahia, estado eleito para ser o carro-chefe da implantação da indústria turística no país, os primeiros inventários sistemáticos de bens culturais realizados na cidade de São Paulo vincularam-se ao planejamento urbano e buscavam diversificar as formas de proteção aos bens culturais.

\section{INVENTÁRIO, PROCEDIMENTOS MÚLTIPLOS}

$\mathrm{O}$ inventário, entre nós geralmente tomado como resultado de um levantamento de campo, pode ser conduzido de diferentes maneiras, e a 
partir de diversos conceitos. Entre eles, segundo denominação de Varine-Bohan (s.d.), há o "inventário empírico", cuja essência é a identificação material de bens remanescentes; dele resulta o arrolamento do produto de processos sociais e culturais, sem que estes sejam considerados, assim como não o são as formas de sua apropriação e o seu lugar na sociedade atual. $\mathrm{O}$ inventário empírico foi um modelo predominante nas práticas brasileiras; note-se que ele se detém no tempo passado e está intrinsecamente submetido aos critérios do observador que o realiza, uma vez que não é orientado por um trabalho de pesquisa que, antecedendo o de campo, forneça informações baseadas no conhecimento já produzido sobre o objeto. Outra possibilidade, continua o mesmo autor, é o “inventário operacional”. Baseado em amplas pesquisas prévias, em estudos sistemáticos das formas culturais dos moradores de uma região, ele conduz a resultados que tendem a esmaecer a ideia estática de História, como se este conhecimento fosse prisioneiro do tempo cronológico, em favor da dinâmica da história. Esta favorece a percepção de que há processos culturais que ultrapassam um dado momento, são permanências, continuidades históricas, que referenciam memórias e sentidos sociais contemporâneos (VARINE-BOHAN, s.d., p. 13). Analisa-se, desse modo, o significado hodierno dos objetos inventariados, o que os aproxima das possibilidades de reapropriação e reinserção na dinâmica cultural.

Entende-se hoje que, com ou sem estudos prévios, o levantamento de campo não é o inventário, e sim a fase de identificação dos bens; dela resulta o inventário, isto é, um conjunto de bens selecionados a partir de critérios preestabelecidos, sobre os quais recairá uma forma de proteção do poder público. De acordo com a Constituição de 1988, o inventário é uma forma de proteção. Alternativa ao tombamento, ele possibilita estabelecer a diferenciação de valores culturais entre os bens assim arrolados e os efetivamente tombados. Portanto, como forma de proteção, o inventário abrandaria as restrições decorrentes do tombamento, em alguns casos excessiva, e contrabalançaria a rigidez que faz esse instrumento jurídico ser encarado como empecilho ao desenvolvimento e ao lucro, e não como vetor de qualidade do ambiente e da vida. Esparsos, assistemáticos e em geral, não utilizados como referência para a abertura de estudos de tom- 
bamento, os inventários também não vêm sendo assumidos como instrumento de gestão do patrimônio cultural ou como referência para orientar intervenções urbanas e obras públicas. ${ }^{8}$

Objeto de contínuas discussões jurídicas, esse instrumento de proteção é objeto de controvérsias, pois sua aplicação ainda não foi regulamentada. Segundo alguns especialistas, ele não pode ser utilizado, enquanto outros entendem que sua aplicação é imediata, uma vez que a preservação do patrimônio cultural é um direito fundamental e difuso. ${ }^{9} \mathrm{~A}$ utilização independeria de regulamentação específica e, na ausência de uma regulação nacional, seria possível aos estados e municípios estabelecerem normas jurídicas próprias, de modo a manter a eficiência da proteção ou, no caso de bens inventariados, abrandar o rigor das restrições impostas pelo tombamento. ${ }^{10}$ Embora juridicamente defensável e, do ponto de vista da preservação, desejável, e apesar dos meritórios esforços já realizados, a utilização do inventário como instrumento de proteção, seleção de bens identificados ou, ainda, como base para o planejamento e gestão do patrimônio cultural esbarra em males crônicos da estrutura administrativa - carência de recursos humanos, de verbas, e crescente burocratização -, mas, também, em certa inércia que inclui aspectos metodológicos.

\section{ENTRE A AÇÃO E O DISCURSO}

Diferentes formas de inventariar são hoje tidas como estruturadoras das demais ações de preservação de bens culturais. As ações aqui abordadas, desenvolvidas no Condephaat nos anos 1970, não atenderam a esta finalidade. Embora o então recente "curso de 74" tivesse promovido reflexões e aberto, no campo do discurso, a adoção de "patrimônio cultural", os profissionais da área eram predominantemente herdeiros das concepções modernistas de arquitetura e do papel do patrimônio explicitados no Congresso Internacional de Arquitetura Moderna (CIAM), cujas conclusões foram consubstanciadas na Carta de Atenas, de 1933.

\footnotetext{
8. Lei n. 10.257, de 10.6.2001, Estatuto da cidade, consagrou a importância da inclusão do patrimônio no planejamento territorial, o que ainda não surtiu resultados efetivos para sua conservação enquanto parte integrante dos espaços urbanos. 9. Entre esses últimos, ver, por exemplo, Miranda (2008).

10. Miranda (2008) baseia seus argumentos na Constituição de 1988, Cap. II- “Dos direitos e garantias fundamentais", Cap. I, art. 5o LXXVIII, $\$ 1$ o.
} 
Prevalecia entre eles a proposta de pontuar a cidade com monumentos isolados que espelhassem o passado em um ambiente urbano, sem efetivamente integrá-los, mas dando o testemunho do avanço representado pela arquitetura e o urbanismo modernos. Isso possivelmente tenha dificultado a aproximação entre duas dinâmicas, a de preservação e a de planejamento urbano. As resistências, que até o momento atual não estão totalmente superadas, não foram menores em relação aos significados não materiais dos bens e ao papel por esses desempenhado na formação de representações mentais. Até o momento, ambos os fatores se refletem nos resultados das ações de proteção a bens culturais e, possivelmente, tenham também constituído uma barreira à absorção do conceito de patrimônio ambiental urbano, uma vez que esta implicava o entendimento da cidade como um objeto cultural, ou seja, cujos significados só podem ser compreendidos como confluência da materialidade e, por assim dizer, do intangível.

A ideia de patrimônio ambiental urbano ganharia, assim, um lugar maior no discurso do que na prática dos órgãos de preservação. De uso corrente, tornou-se sinônimo de uma renovação ansiada, de algo que parecia tornar possível "superar as restrições e deformações reducionistas implicadas em outros conceitos em voga [...]", como observou Meneses (1978). De fato, os já consagrados critérios e métodos utilizados para identificar o patrimônio permaneciam sob um novo rótulo, o que, ainda de acordo com Meneses (1978), se originou no desconhecimento de que o "patrimônio ambiental urbano é, antes de mais nada, um fato social, produto de uma sociedade específica, e que é só na prática social que ele poderá ser apreendido".

A diversidade de opiniões relativas aos conceitos e procedimentos técnicos de inventário permaneceria. Em agosto de 1980, promovido pelo Iphan, pelo governo da Bahia e pela Fundação Roberto Marinho, realizou-se, em Salvador, o I Encontro sobre Inventários de Proteção ao Patrimônio Cultural. As recomendações finais do evento foram agrupadas em dois vetores: o da concepção de inventário e o dos instrumentos de apoio à sua realização, nos quais se revela uma mudança de perspectiva, agora mais aproximada ao que fora indicado por Varine-Bohan. Entre outros pontos, o documento recomendava que os órgãos de proteção ao patrimônio definissem políticas de preservação e que as políticas locais de catalogação e 
inventário fossem implementadas, assim como o fosse a participação das comunidades no processo de identificação de bens culturais. A perspectiva de participação da sociedade, havia muito represada, também se manifestou nas recomendações de amplo acesso às informações obtidas nos inventários e no reconhecimento das iniciativas espontâneas de identificação de bens culturais. Entre os instrumentos de apoio, consignaram-se a necessidade de exame de modelos alternativos de inventário e o desenvolvimento de um projeto piloto para testar os recursos modernos aplicáveis. Os debates da década de 1980 giraram em torno do como conduzir o inventário e do como torná-lo um instrumento de proteção que, diferenciado do tombamento, fosse uma medida cautelar que representasse, com propriedade, o reconhecimento de valores culturais detectados na identificação de bens. A Constituição de 1988 absorveria essa preocupação, mas a prática de utilização do inventário como forma de proteção ainda permanece restrita.

\section{A DIFÍCIL RENOVAÇÃO}

A ideia de estabelecer o inventário como um procedimento de trabalho foi manifesta no Condephaat no início de suas atividades. Pretendia-se, então, incluir entre os bens inventariados os documentos históricos e iconográficos e "as demais fontes para a História da Arte no Brasil", bem como promover a catalogação sistemática dos arquivos oficiais e particulares, o que expressa uma visão idealista de atuação. ${ }^{11}$

Desde então, inúmeras propostas foram elaboradas por conselheiros e técnicos, e realizaram-se inventários esparsos, de centros históricos, de bairros e temáticos, sem que a identificação de bens culturais se tornasse uma atividade sistemática e constante. As restrições geradas pela ausência da percepção ampla propiciada pelos inventários somavam-se àquelas decorrentes da perspectiva histórica por longo tempo adotada.

Embora na década de 1970 já se processasse a renovação da historiografia, com a inclusão, além de outros, do estudo de temas cotidianos e dos processos culturais, o órgão estadual baseava suas ações em uma interpretação economicista da sociedade, a partir de "ciclos econômicos".

11. Processo Condephaat n. 00078/71. 
A partir de uma compreensão mecanicista da História se definiam o território a ser abrangido em inventários e os critérios de valorização de bens culturais. Até mesmo no caso de "cidades históricas" refletia-se a interpretação economicista por meio de expressões até hoje largamente utilizadas, como "cidade do café". A sociedade era vista, assim, como algo estaticamente organizado em infraestrutura e superestrutura, nessa situando-se a esfera da cultura. Desse modo, nublava-se a percepção da diversidade cultural e da multiplicidade de objetos que a representava. Nesse sentido, também foi marcante a valorização da tradição das elites; ela reforçaria a já consagrada prática preservacionista centrada na arquitetura como representação quase exclusiva da cultura, o que é visível nos inventários realizados na década de 1970, todos relativos a bens arquitetônicos.

Vagarosamente, novas perspectivas começariam a partir da segunda metade dessa década. Em 1972, o então diretor do Serviço Técnico de Conservação e Restauro, arquiteto Carlos Lemos, retomou a proposta de realização de inventários sistemáticos organizados por regiões e desenvolvidos gradualmente, já constante em documento anterior em que se explicitavam as funções dos técnicos. ${ }^{12} \mathrm{~A}$ necessidade de inventários era uma preocupação constante, também explicitada em inúmeras propostas produzidas pelos técnicos e conselheiros e encaminhadas aos secretários de governo reivindicando melhores condições de trabalho para o melhor desempenho do órgão. ${ }^{13}$

A ausência de documentos impossibilita o acompanhamento sequencial da proposta de Lemos. No acervo do Condephaat há dois trabalhos desse período, um deles sem data, que mais se assemelham a

\footnotetext{
12. Processo Condephaat n. 00078/71.

13. Ver, por exemplo, "Diretrizes para a formulação de uma política de atuação do Condephaat", reproduzido na Ata n. 608, de reunião ordinária do Conselho, de 18.6.1984. Nela se apontaram conceitos orientadores da ação do órgão, entre eles, patrimônio ambiental urbano, e a importância de procedimentos como o inventário, assim como a necessidade de articulação com órgãos de planejamento urbano e regional. Definiram-se também as linhas de atuação: identificação, que exige "pesquisa científica de natureza histórica, sociológica e antropológica, recobrindo investigação arquitetônica, geográfica e outras"; recomendava-se entendimento com instituições de pesquisa; proteção: física (conservação, restauro), legal (respeito às restrições, fiscalização e sanções); e social (uso); e valorização: inclui os usos que englobem o universo cotidiano e do trabalho.
} 
levantamentos de edificações isoladas do que propriamente a peças de um inventário. Em ambos não se explicitam critérios, o que sugere que o produto resultante, a ficha com informação histórica e de construção, fotografias, planta da unidade e descrição sumária, constituía a finalidade pretendida. Em Itu, foram registradas seis edificações, incluídas as da Fábrica de Tecidos São Luiz e o sobrado do Museu Republicano. ${ }^{14} \mathrm{O}$ da cidade de Campinas data de 1979. ${ }^{15}$

Um conjunto de seis volumes, cada um referente a uma cidade, forma o documento que mais se aproxima da proposta de Lemos, e pode ser tomado como exemplo de inventário temático, regional, de técnicas e sistemas construtivos de edifícios rurais e urbanos no Vale do Paraíba, realizado em $1976 .{ }^{16}$ Contendo levantamentos métrico e fotográfico, e detalhados desenhos de grande beleza e valor informativo sobre as edificações, entre as quais se incluem lugares de produção de farinha de mandioca, açúcar e aguardente, componentes de complexos de produção agrícola classificados apenas como monocultores, ele trouxe a diversidade de configurações espaciais das propriedades rurais e integrou o mundo do trabalho ao mundo da casa grande, o que até então era inédito. Também forneceria subsídios para a realização de projetos de restauro. Suas qualidades, porém, não foram suficientes para projetá-lo como instrumento propiciador da continuidade das ações de proteção aos bens culturais no Vale do Paraíba.

As possibilidades de renovação dos procedimentos de inventário no Condephaat ganharam força a partir de 1976, até 1979, período em que a presidência do Conselho foi exercida pelo arquiteto Nestor Goulart Reis Filho. Na primeira reunião do novo conselho, o presidente propôs a fixação de diretrizes para política de preservação e restauração a partir da elaboração de listagem para análise e subsequente levantamento, identificação e classificação setorial do patrimônio cultural. ${ }^{17} \mathrm{Na}$ reunião seguinte, o conselheiro Ulpiano Bezerra de Meneses apresentou uma proposta de atuação do colegiado e Aziz

\footnotetext{
14. Trabalho desenvolvido por Julio Abe Wakahara. Cedoc-Condephaat, sem localização.

15. Os responsáveis foram José Saia e Odair Carlos de Almeida. Cedoc-Condephaat, sem localização. 16. O trabalho foi realizado por Antonio Luiz Dias de Andrade, Janjão; Luiz Alberto de Prado Passaglia; e Odair Carlos de Almeida.

17. Ata n. 285, reunião ordinária do conselho, de 1.6.1976.
} 
Ab' Saber, o trabalho Recursos paisagísticos do Brasil, dando início às pioneiras ações de proteção de áreas naturais pelo tombamento. ${ }^{18}$

Procurou-se também ampliar a perspectiva do Condephaat em relação às questões urbanas. Possivelmente, em atenção a este aspecto, promoveu-se uma "experiência piloto", cujo alvo foi a cidade de Itu; pretendia-se desenvolver aí uma "ação cultural integrada", que fornecesse bases para a atuação futura do órgão. A proposta elaborada por profissionais contratados foi acatada pelo Conselho ainda em junho de $1976 .{ }^{19} \mathrm{O}$ projeto foi dividido em duas fases: na primeira, levantamento, análise de dados e diagnóstico; na segunda se apresentariam as normas, padrões de desenvolvimento e proposições para implantação do Programa de Ação Cultural na cidade. Segundo o termo de referência, tratava-se da "formulação de normas e criação de condições que integrem e valorizem os diversos tipos de patrimônios culturais: monumental, urbano, paisagístico, artefatual e comportamental". Essa fase não seria contratada e a ação pretendida permaneceu inconclusa.

O diagnóstico, entre outros itens, incluiu o levantamento para caracterização do espaço físico local e regional; dos recursos turísticos, a atualização cartográfica e o inventário do acervo cultural existente, incluindo os documentais e coleções, as tradições religiosas e as manifestações populares, de hábitos, costumes, e da linguagem. Tratava-se de abordar um amplo espectro de manifestações, o que diferenciava este dos trabalhos anteriormente realizados, sempre presos ao campo da manifestação arquitetônica. A equipe técnica foi composta por profissionais experientes de diversas especialidades, entre os quais economistas, sociólogos e geógrafos, o que era incomum. ${ }^{20}$

O Relatório Final da primeira etapa, composto por vários volumes, contém análises realizadas sob diferentes pontos de vista além de fichas que compõem o conjunto Inventário do acervo cultural (IAC). Nelas, além da fotografia e planta abordam-se os tópicos referentes aos

18. Ata de reunião ordinária do Conselho n. 286, de 7.6.1976.

19. "Estudo e análise da arquitetura urbana de Itu”, escritório de João Walter Toscano Arquitetos Associados.

20. Compunham a equipe: João Walter Toscano, Massayoshi Kamimura, Odiléa Setti Toscano, Octávio Ianni, Constantino Ianni, Julio Abe Wakahara, Kilsa S. de Castro Lima, Helmut Troppmair e Jaelson B. Trindade. Relatório Final, Cedoc - Condephaat. 
bens registrados: situação e ambiência; utilização atual; estado de conservação; e dados cronológicos. ${ }^{21}$ De acordo com o Relatório Final, ${ }^{22}$ a análise da morfologia urbana, isto é, das relações espaciais da cidade, se apresenta como "testemunho de todos os fatos urbanos" e, por isso, catalisaria todas as vertentes estudadas. A síntese das abordagens realizadas convergia para a cidade tomada como estrutura espacial. Mostrou-se também a "urgência de uma ação protetora em termos de legislação urbanística para o conjunto da cidade e de uma maior atenção das autoridades aos monumentos tombados", além da obtenção do apoio e interesse da população local. ${ }^{23} \mathrm{O}$ trabalho, embora não concluído, apontou para a importância da colaboração entre profissionais de diversas especialidades e de análises sobre as relações contemporâneas da população com o patrimônio cultural, bem como das pressões econômicas sobre sua conservação.

Entre maio de 1979 e setembro de 1982, no decorrer da gestão de Ruy Othake, as perspectivas de identificação de bens culturais voltariam a se estreitar. Sob a égide da prevalência dos conceitos de patrimônio e monumento históricos, os inventários voltariam a privilegiar apenas bens arquitetônicos. Os inventários então realizados limitaram-se ao registro fotográfico de edificações antigas em 36 vilas selecionadas segundo um mapa de São Paulo datado de 1846, acompanhado de um texto que pretendia estabelecer critérios de classificação dos bens arquitetônicos para o Conselho, o que não foi aceito pelo colegiado que entendeu ser conveniente deixar em aberto o corpo teórico e conceitual do órgão, de modo a possibilitar enfoques diferenciados. ${ }^{24}$

\section{REFERÊNCIAS}

AZEVEDO, Paulo Ormindo. Por um inventário do patrimônio cultural brasileiro. Revista do Patrimônio Histórico e Artístico Nacional, n. 22, 1987.

\footnotetext{
21. Diagnóstico Geral da Cidade de Itu. Relatório Final. Odiléa Helena Setti Toscano e João Walter Toscano. Cedoc - Condephaat.

22. Relatório Final, volume I, Introdução.

23. Relatório Final, volume I, Introdução.

24. O registro fotográfico foi coordenado por Gustavo Neves da Rocha Filho; o autor do texto é Julio Katinsky. Atas de reunião ordinária do Conselho n. 484, de 16.9.1981, e n. 484, 16.9.1981.
} 
BAFFI, Mirthes I. S. O IGEPAC-SP e outros inventários da Divisão de Preservação do DPH: um balanço. Revista do Arquivo Municipal, n. 204, p. 169-191, 2006.

CORREIA, Belize Câmara. A tutela judicial do meio ambiente cultural. Revista de Direito Ambiental, São Paulo, n. 34, v. 9, p. 41, 2001.

CURY, Isabelle (Org.). Cartas patrimoniais. Rio de Janeiro: Iphan, 2009.

LEAL, Claudia F. Baeta. As missões da Unesco no Brasil: Michel Parent. Rio de Janeiro: Iphan; Cepedoc, 2008.

MARINO, Mônica Cristina. Tutela jurídica do patrimônio cultural: atuação do Ministério Público Estadual. Apresentação no Curso de Difusão "Proteção de bens culturais: concepções e práticas", no CPC-USP. Casa de D. Yayá, São Paulo, ago. 2015.

MENESES, Ulpiano Bezerra de. Patrimônio ambiental urbano: do lugar comum ao lugar de todos. CJ Arquitetura, n. 19, 1978.

MIRANDA, Marcos Paulo de Souza. O inventário como instrumento constitucional de proteção ao patrimônio cultural brasileiro, 2008. Disponível em: <https://jus.com.br/artigos/11164/o-inventario-como-instrumento-constitucional-de-protecao-ao-patrimonio-cultural-brasileiro $>$. Acesso em: 27 fev. 2016.

MOTTA, Lia; SILVA, M. Beatriz Resende (Org). Inventários de identificação: um panorama da experiência brasileira. Rio de Janeiro: Iphan, 1998.

VARINE-BOHAN, Hügues. A experiência internacional. Notas de aula 12.8.1974. São Paulo: FAU-USP; Iphan, s. d.

\section{Recebido}

06/03/2016

\section{Aprovado}

$16 / 06 / 2016$ 